\title{
Contabilidad nacional medioambiental para productores de petróleo. Estimaciones para México y Venezuela (1901-1985)
}

\author{
Environmental historical national accounts for oil producers. \\ Estimates for Mexico and Venezuela (1901-1985)
}

\author{
MARÍA DEL MAR RUBIO VARAS \\ Universidad Pompeu Fabra, Barcelona
}

\begin{abstract}
RESUMEN
La contabilidad medioambiental ha demostrado que la prosperidad basada en el agotamiento de recursos naturales puede ser un espejismo. La contabilidad nacional tradicional ignora el empobrecimiento del stock de recursos naturales. Desde la perspectiva medioambiental, esta omisión conduce a exagerar el ingreso, incita a niveles de consumo insostenibles y produce una falsa impresión a la hora de valorar las perspectivas económicas de aquellos países que basan su economía en la extracción de recursos naturales. Al mismo tiempo, la historiografía de los países productores de petróleo está llena de referencias, que partiendo de premisas muy diferentes y sin apenas evidencia cuantitativa, llegan a conclusiones muy similares a las recientemente expresadas desde la contabilidad medioambiental. El presente estudio es el resultado de unir estas dos literaturas y aprovechar las sinergias resultantes. Además de contribuir al sorprendentemente pequeño número de estudios comparativos de Venezuela y México, este artículo representa un primer examen de la eficacia y utilidad de la contabilidad medioambiental como herramienta de análisis económico en el largo plazo.
\end{abstract}

PALABRAS CLAVE: Recursos no renovables, Contabilidad medioambiental, Producto Nacional Neto, Petróleo, México, Venezuela

Códigos JEL: Q01, N5, P24

\section{ABSTRACT}

Environmental accounting literature reminds us that prosperity can be ephemeral if it is built on depletion of natural resources. Traditional national accounting practice ignores the loss of natural resources. According to standard environmental accounting, this produces exaggerated income, encourages unsustainable levels of consumption and is misleading when assessing the economic prospects of resource extracting countries. While the historiography of oil-extracting countries departs from entirely different concepts and methods, it contains plenty of arguments that resemble those of the environmental accountants. Nonetheless the arguments in the historiography lack quantitative support for the most part. This article connects these previously disparate literatures and explores the resulting synergies. Doing so, it contributes to the surprisingly small amount of comparative historical studies of the oil industries and the economic histories of Venezuela and Mexico, but overall, this study is an examination of the tractability and usefulness of environmental accounting as a tool of economic analysis over the long run.

KEY WORDS: Exhaustible resources, Environmental accounts, Net National Product, Petroleum, Mexico, Venezuela

JEL Codes: Q01, N5, P24 


\section{Introducción ${ }^{1}$}

$\mathrm{E}$ n este artículo se combinan conceptos de historia económica y contabilidad medioambiental para desarrollar lo que bien podría llamarse "contabilidad nacional medioambiental histórica". Se examina cuán manejable y útil puede llegar a ser la contabilidad medioambiental como instrumento de análisis económico en el largo plazo. Las historias económicas del siglo XX de dos productores de petróleo, Venezuela y México, se analizan a la luz de los métodos de contabilidad nacional. Es esperable que la contabilidad medioambiental sea relevante para estos dos países, dado el peso que los recursos naturales, especialmente el petróleo, han tenido en su desarrollo económico. Comenzaremos por responder algunas preguntas básicas que explicitan la motivación de este estudio: ¿por qué es la contabilidad ambiental relevante para la historia económica?, ¿cuáles son los principales temas investigados?, ¿por qué centrarse en los productores de petróleo?, ¿por qué éstos dos productores?, ¿hay ventajas en aplicar métodos de contabilidad medioambiental a series históricas?, y, finalmente, ¿cuáles son las implicaciones de esta investigación?

Una vez resueltas estas cuestiones, se presentan brevemente algunos principios básicos de la teoría y los métodos de contabilidad medioambiental más utilizados. Por último, se procede a mostrar la aplicación empírica de esos modelos a los casos concretos de México y Venezuela. La única ambición de este artículo es la de ser un escueto resumen de los resultados obtenidos de aplicar los métodos de contabilidad medioambiental a series históricas y las lecciones que de ello se derivan tanto para la historia económica como para la contabilidad medioambiental.

\section{Motivación del estudio}

\section{1. ¿Por qué es la contabilidad ambiental relevante para la historia económica?}

En primer lugar, la estimación y análisis del desempeño económico en el largo plazo y sus métodos de evaluación son centrales en la historia económica. Los historiadores económicos han hecho grandes esfuerzos para construir series históricas de

[Fecha de recepción del original, diciembre de 2005. Versión definitiva, octubre de 2006]

El presente artículo tiene su origen en la tesis doctoral de la autora, leída en la London School of Economics en 2002. La misma fue premiada por el jurado de la Asociación Internacional de Historia Económica como la mejor tesis doctoral de historia económica producida entre 2001 y 2005 en la categoría de siglo XX. El premio fue otorgado en 2006 en el XIV Congreso Internacional de Historia Económica (Helsinki, 21-25 agosto 2006). Agradezco sus sugerencias a los evaluadores anónimos de Investigaciones de Historia Económica. 
ingreso y output para un número creciente de países ${ }^{2}$. La contabilidad nacional, y el Producto Interior Bruto (PIB) en particular, se han convertido en pieza elemental del análisis del cambio económico y los diferentes modelos de desarrollo existentes, ayudando a entender el presente y proyectar mejor el futuro. La contabilidad medioambiental ha contribuido a extender el reconocimiento de que el ingreso nacional de economías basadas en los recursos nacionales nunca se ha calculado de manera exacta. Esta literatura sostiene que ignorar el empobrecimiento del stock recursos naturales, vía degradación o agotamiento, en los cálculos de ingreso y producción nacional enmascara, tras la falsa apariencia de una economía nacional boyante, la destrucción de los recursos disponibles para el futuro ${ }^{3}$.

Un país puede consumir más (o crecer) como resultado de aumentar su productividad, o puede consumir una mayor cantidad de bienes agotando más rápidamente los recursos económicos a su disposición, por ejemplo, el capital natural disponible. Considérese el caso hipotético extremo de un país cuya economía se basa simplemente en la exportación de un recurso natural no renovable y la importación de todo lo necesario gastando íntegramente las rentas generadas por la exportación. Supóngase, además, que no existe coste alguno asociado a la obtención del recurso y ninguna otra producción dentro del país. El ingreso de este país, medido de manera tradicional, podría ser enorme e incluso crecer en el tiempo. Sin embargo, medido utilizando la contabilidad medioambiental, el consumo habido no se correspondería con el ingreso disponible, sino que se estaría produciendo a costa del empobrecimiento del país al arruinar el capital natural y no hacer las provisiones (inversiones) oportunas para reemplazarlo. Los contables medioambientales argumentan que las prácticas de contabilidad nacional tradicional exageran el ingreso, alientan niveles de consumo insostenibles en el largo plazo y oscurecen la necesidad de poner en marcha medidas de ajuste urgentes en países donde el consumo se financia a costa del empobrecimiento de recursos naturales. A priori, las correcciones propuestas desde la contabilidad medioambiental tenderían a ser de una magnitud considerable para todos aquellos países que presenten similitudes con el caso hipotético planteado.

\section{2. ¿Cuáles son los principales temas investigados?}

Una de las tareas principales de este trabajo es cuantificar las afirmaciones de la contabilidad medioambiental. En otras palabras, en qué medida difiere ésta de la conta-

2 Entre los clásicos, y sin intención de nombrarlos a todos, véanse Kuznets (1951), Deane y Cole (1959), Ohkawa (1957), Feinstein (1972), Prados (1988) y Baptista (1991).

3 Dasgupta y Mäler (1991), p. 101. 
bilidad nacional tradicional. Las series históricas de ingreso y producto, como las de Maddison, usadas de manera habitual como punto de partida para la evaluación de la trayectoria económica en términos históricos, no reconocen en ningún caso las especiales características del ingreso generado en economías basadas en los recursos naturales ${ }^{4}$. Si las alegaciones de la contabilidad nacional fueran correctas, las estadísticas tradicionales de estos países estarían ofreciendo una visión inexacta del progreso habido y de las perspectivas económicas futuras de los mismos. Son precisamente los historiadores económicos los responsables de que nuestro conocimiento del ingreso, la producción y la riqueza nacional no sea ni mucho menos estático. Las estimaciones históricas son sometidas constantemente a revisión, se construyen nuevos y mejores índices, se incluyen nuevas series, se aplican nuevas técnicas a series ya conocidas, etc. Todo lo cual se traduce en matizaciones de las conclusiones previas y, en algunos casos, en nuevas interpretaciones. La investigación que aquí se presenta enlaza con este espíritu de constante revisión de los modos de medir el ingreso. Y el hecho de que se centre en dos economías latinoamericanas no deja de ser una contribución más, dado que es de sobra conocido que la historia cuantitativa latinoamericana está todavía por escribirse en su mayor parte ${ }^{5}$.

\section{3. ¿Por qué centrarse en los productores de petróleo? ¿Por qué los dos productores escogidos?}

La divergencia entre las mediciones tradicionales de ingreso y las medidas de ingreso medioambiental es más importante en países que explotan recursos no renovables $^{6}$. De entre los recursos no renovables es difícil pensar en alguno que haya influido más que el petróleo en la economía de los países que lo poseen durante el siglo XX. Además de su naturaleza de recurso no renovable y de la incuestionable importancia de los réditos obtenidos por parte de los países productores, el hecho de que su explotación se haya llevado a cabo durante más de un siglo justifica la elección de dos países productores de petróleo para evaluar la utilidad de la contabilidad medioambiental en el largo plazo.

México y Venezuela han sido productores de crudo desde los albores de la era del petróleo 7 . México comenzó su explotación en 1901 y se convirtió en el principal exportador y segundo productor del mundo en 1921, sólo por detrás de los Estados

\footnotetext{
Maddison (1995).

Véase a este respecto la introducción del libro de Coatsworth y Taylor (1999).

El Serafy (1989), p. 10.

Para un repaso de la literatura y de las distintas fases de la historia petrolífera de ambos países, Rubio (2002), cap. 1.
} 


\section{GRÁFICO 1}

PRODUCCIÓN DE PETRÓLEO Y CONSUMO NACIONAL EN MÉXICO Y VENEZUELA, 1901-1990*

(miles de barriles)

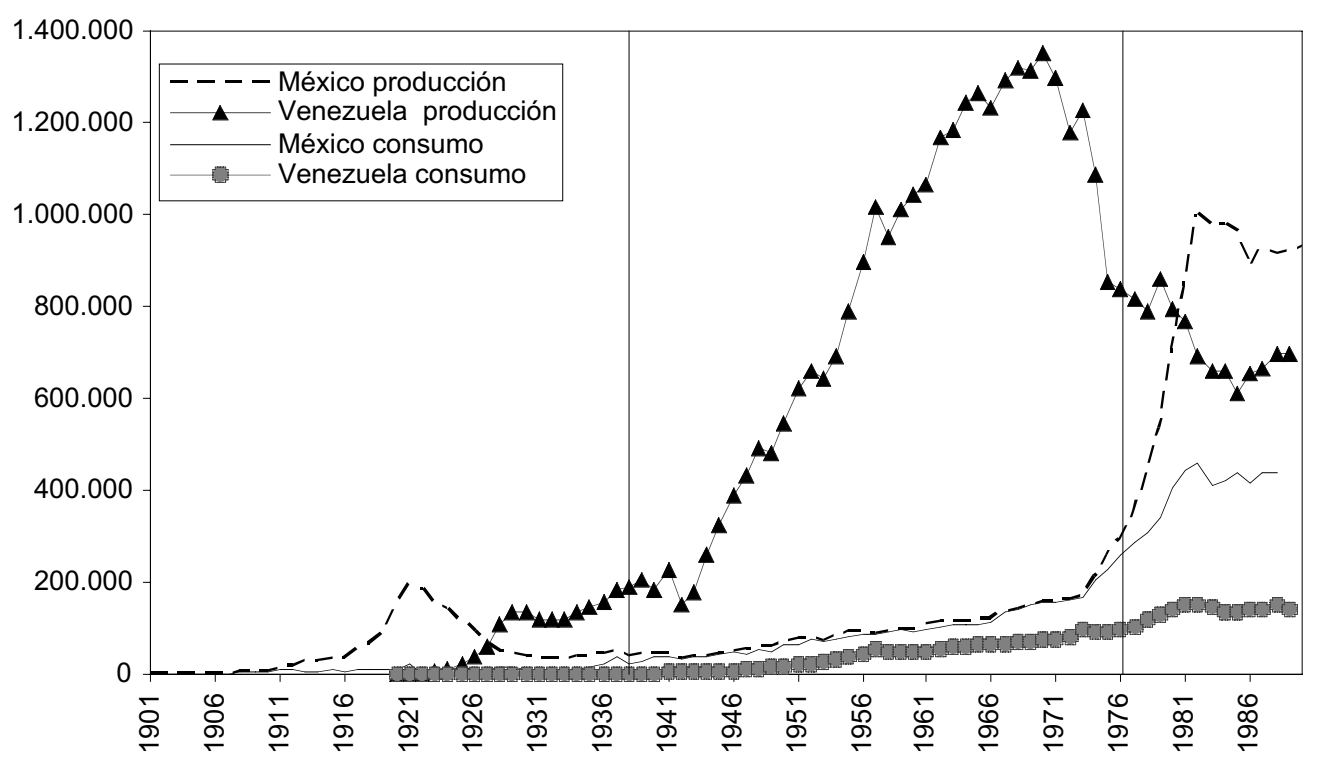

* Las líneas verticales señalan las fechas de nacionalización de la industria, 1938 en el caso de México y 1976 en el de Venezuela.

Fuentes: Baptista (1997) para la producción de petróleo de Venezuela (1920-1990); INEGI (1994a) y (1994b) para la de México (1901-1992). El consumo doméstico fue estimado restando las exportaciones. Para las fuentes de las exportaciones petroleras, véase Rubio (2004), Apéndice B.

Unidos. Venezuela, cuya producción tomó cuerpo tras la I Guerra Mundial, relevó a México a finales de la década de 1920. Ambos países han confiado en el petróleo como sustento de sus economías y motor de desarrollo en distintos momentos de su historia. Como se observa en los Gráficos 1, 2 y 3, sus estrategias se entrelazan.

El que ambos países siguieran caminos opuestos en sus políticas petroleras desde muy temprano es también relevante para los temas que se investigan aquí. Mientras que México nacionalizó la industria en 1938, expropiando a las compañías extranjeras que habían llevado a cabo la explotación hasta entonces, y siguiendo después una estrategia de desarrollo hacia dentro (extrayendo únicamente el petróleo necesario para alimentar la demanda interna), Venezuela adoptó la estrategia exportadora pura, dejando en manos de capital internacional su industria petrolera hasta 1976, cuando también la nacionalizó. En ese mismo año, el descubrimiento de nue- 


\section{GRÁFICO 2}

EXPORTACIONES PETROLERAS COMO PORCENTAJE DEL VALOR DEL TOTAL EXPORTADO POR MÉXICO Y VENEZUELA, 1911-1990

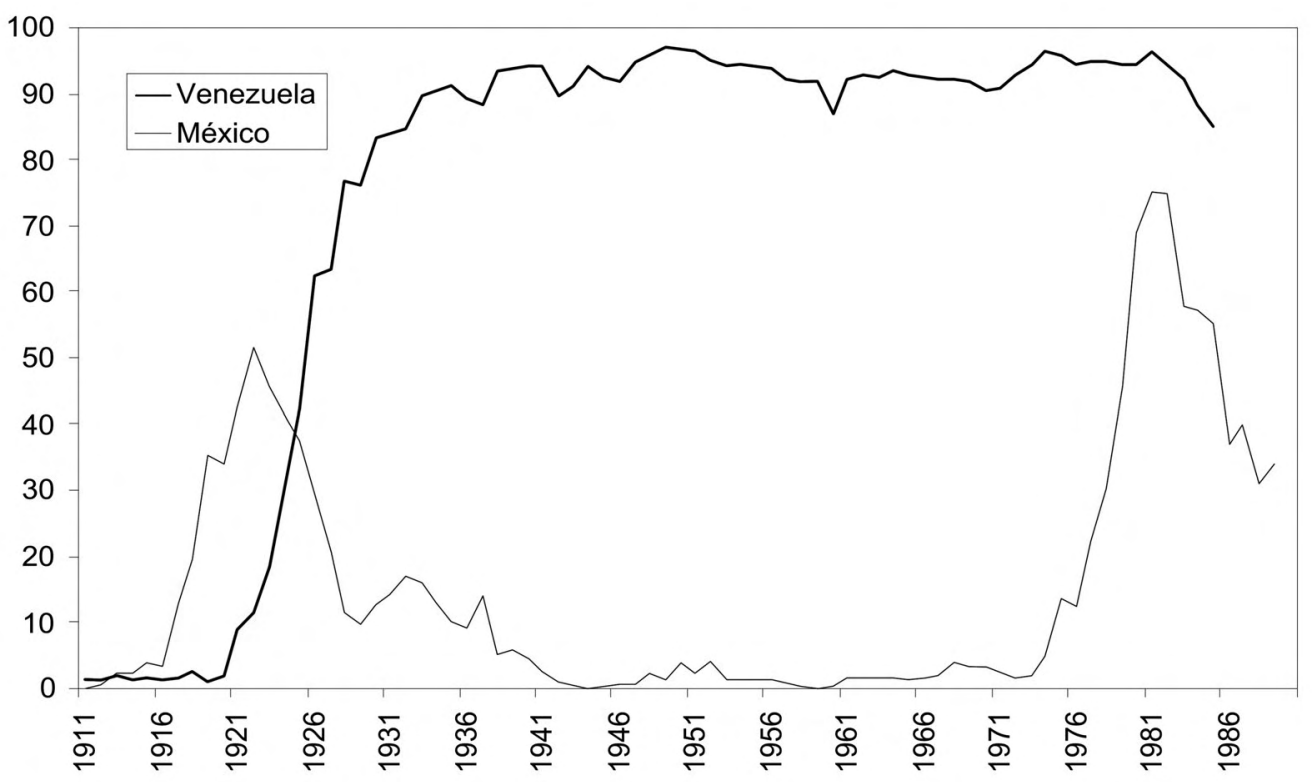

Fuentes: Rubio (2004), Apéndice B.

vos yacimientos hizo que México retomara la vía exportadora. Luego de más de cuarenta años de observarse en la distancia con una mezcla de escepticismo y asombro, defendiendo cada cual que su estrategia era mejor que la del otro, ambos países alcanzaron el final del siglo XX como productores de petróleo de cierto peso en el mercado mundial, y con su explotación bajo el control de sus respectivos gobiernos.

Las historias de México y Venezuela no sólo tienen en común su herencia histórica; también sus respectivas industrias petroleras se han visto afectadas por los desarrollos habidos en uno y otro país. Durante el primer cuarto de siglo XX, la industria petrolera venezolana se vio influida por los avances de la industria de México, mientras que durante los cincuenta años siguientes, las acciones de Venezuela marcarían el destino de la industria petrolera a nivel mundial. Políticos, empresarios y académicos de ambos países nunca perdieron del todo de vista la política del otro: los nacionalistas venezolanos, que los hubo, observaron con envidia la capacidad mexicana de gestionar su propia riqueza petrolera, mientras que en México la gestión venezolana no dejó de ponerse como ejemplo de explotación 


\section{GRÁFICO 3}

INGRESO FISCAL COMO PORCENTAJE DEL INGRESO FISCAL TOTAL

DE MÉXICO Y VENEZUELA, 1906-1988

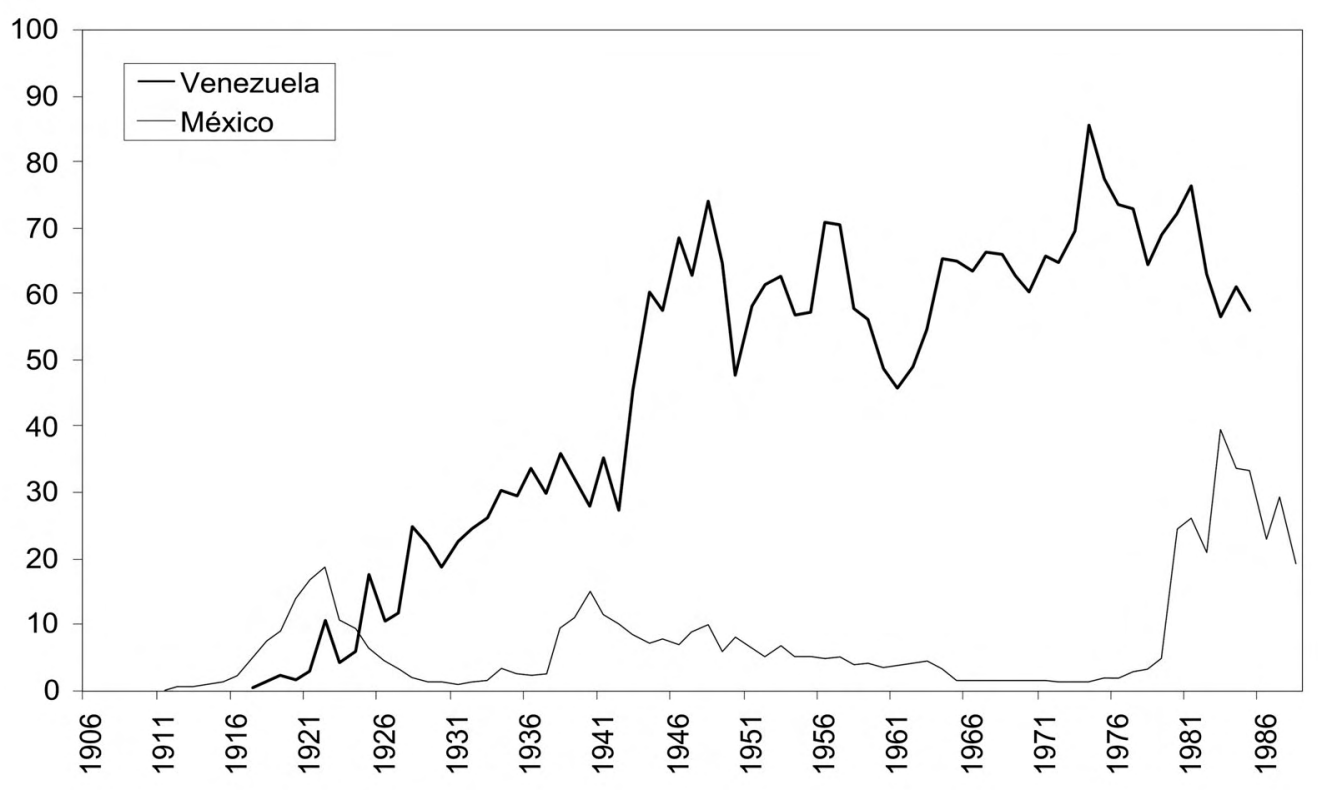

Fuentes: Rubio (2002), Apéndice C.

imperialista de la riqueza nacional. Pese a lo evidente de los lazos y los contrastes entre ambas economías, el número de estudios comparativos es sorprendentemente escaso $^{8}$.

Según lo expuesto hasta aquí, la estrategia venezolana se asemeja bastante al caso hipotético planteado más arriba: su economía se basó en la exportación de un recurso no renovable, la cual financió el grueso de las importaciones; por el contrario, la táctica más conservacionista de los mexicanos se aproxima más al modelo de una economía cerrada, al menos en el período 1938-1976 en cuanto al petróleo. En principio, si seguimos las premisas de la contabilidad medioambiental, el ingreso

8 Éstos se concentran en el primer o en el último tercio del siglo XX. Para los primeros, véase Acosta (1941), que muestra una clara oposición a las políticas del gobierno venezolano y a las compañías, y Matos (1939), que toma una perspectiva antiimperialista. Para el período post-boom petrolero, véanse Kaplan (1981) y Palacio (1996). La única excepción para el lapso intermedio es Thynne (1995). 


\section{GRÁFICO 4}

ÍNDICES DEL INGRESO POR HABITANTE EN SEIS PAÍSES LATINOAMERICANOS, 1900-2000

( media anual de los seis países $=100$ )

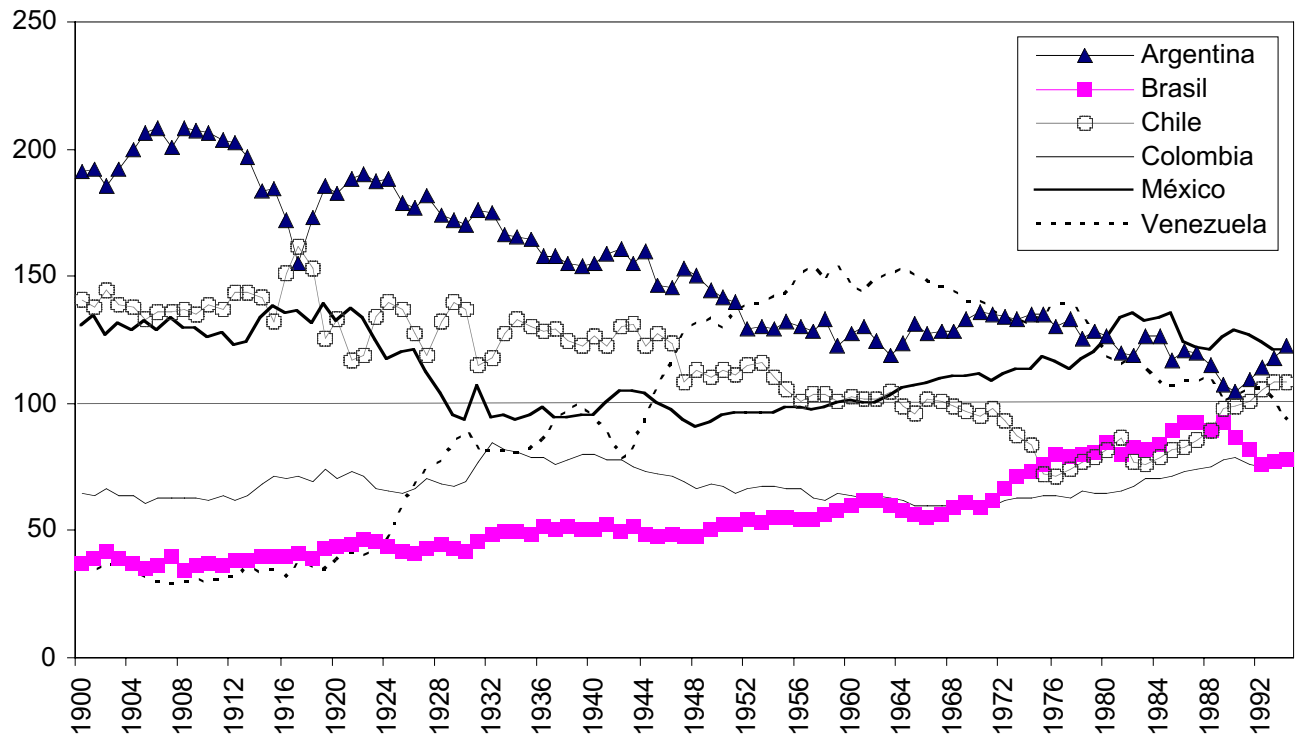

Fuentes: Las cifras de PIB por habitante de Hofman (2000), pp.156-157.

de Venezuela medido de modo tradicional, cuya evolución comparada recoge el Gráfico 4, debería ser bastante distinto del ajustado por el uso de recursos naturales, diferencia que, en el caso mexicano, tendría que ser mucho menor durante la mayor parte del siglo XX, al menos en el lapso 1938-1974. En este contexto, cabe preguntarse si la contabilidad medioambiental puede contribuir a discernir la eficiencia de estas dos estrategias económicas y sus implicaciones para un desarrollo sostenible a largo plazo 9 .

9 El lector debe estar al tanto del uso polisémico que se hace del término sostenible/sustentable. Este artículo restringe el uso a un "ingreso sostenible" en el sentido de Hicks, que se define más abajo. Existen los conceptos de "sostenibilidad débil" de David Pearce (que admite la sustitución de "capital natural" y otras formas de capital) y de "sostenibilidad fuerte" de Herman Daly (que consiste en no extraer un recurso no renovable a un ritmo superior a su tasa de sustitución por otro renovable que aporte en el futuro, al menos, un servicio equivalente). En ambos casos, la idea de sostenibilidad exigiría, para el ejemplo estudiado, hurgar en el uso de los ingresos del petróleo. En este sentido, los ejercicios del presente artículo se encontrarían más próximos sin duda al concepto de sostenibilidad débil. 
También es relevante que tanto mexicanos como venezolanos de distintas épocas fueran conscientes de la prosperidad efímera que encierran las economías basadas en los recursos naturales. La literatura y la historiografía de estos dos países están llenas de argumentos similares a los esgrimidos desde la contabilidad medioambiental ${ }^{10}$. En el caso de Venezuela se ha argumentado elocuentemente que la riqueza petrolera "abrió una brecha cada vez mayor entre la capacidad productiva real de aquella sociedad y sus posibilidades de ganancia"11. También se ha dicho que "tras décadas de consumir más de lo que producían, para volver al equilibrio, los ingresos y el consumo real de los venezolanos tendrán que reducirse"12. Por su lado, los mexicanos temían que, en caso de seguir por la senda de comienzos del siglo XX, su progreso sería falsamente ilusorio y terminaría un buen día sin previo aviso ${ }^{13}$. No obstante, los razonamientos de la literatura contemporánea y la historiografía se basan mayoritariamente en evidencias cualitativas, excepto quizá los esfuerzos de los evaluadores de la llamada "siembra del petróleo" en Venezuela ${ }^{14}$. Los contemporáneos carecían de los conceptos y los métodos que la contabilidad medioambiental ofrece para cuantificar sus argumentos, aunque las intuiciones estaban presentes en sus discusiones. La contabilidad medioambiental nacional en términos históricos tiene potencial para cubrir este hueco.

\section{4. ¿Hay ventajas en aplicar métodos de contabilidad medioambiental a series histó- ricas?}

En principio, parece razonable ajustar los indicadores tradicionales de producción e ingreso para que tengan en cuenta los recursos medioambientales, en especial aquéllos no renovables. Más de dos décadas de trabajos dedicados a la contabilidad medioambiental han demostrado, sin embargo, que existen obstáculos significativos a la hora de construir estimaciones de ingreso y producción que incluyan al medio natural. Además de los problemas conceptuales puramente teóricos, los impedi-

10 Un amplio análisis de las historiografías mexicana y venezolana desde esta perspectiva se puede encontrar en Rubio (2002).

11 Uslar (1985), aquí tomado de Mieres (1989). Esta idea aparece en todos sus trabajos, véanse Uslar (1936), (1945) y (1966). La disparidad creciente entre consumo y producción en Venezuela también se refleja en Mommer y Baptista (1983), p. 3. Es más, Rodriguez y Sachs (1999, p. 278) argumentan que las economías con una relativa abundancia de recursos naturales pueden crecer más despacio porque, precisamente, resulta probable que vivan por encima de sus posibilidades, al permitirles su riqueza medioambiental obtener niveles extraordinarios (e insostenibles) de consumo.

12 Naim y Piñango (1974).

13 Sanginés (1938).

14 Arcila (1989), o también los trabajos comentados en Carrillo (1968). 
mentos de mayor calado tienen que ver con la estimación de flujos y stocks de capital natural y la valoración monetaria de $\operatorname{los} \operatorname{mismos}^{15}$. Es obvio que un estudio histórico como éste no escapa a tales problemas. Una gran parte del tiempo dedicado a esta investigación se invirtió precisamente en elaborar las series de datos necesarias $^{16}$. De hecho, se ha escrito que "un programa nacional de contabilidad medioambiental debe ser de largo plazo, dado que elaborar las series necesarias lleva tiempo y que, a la vez, el análisis de los impactos medioambientales requiere series de largo plazo"17. Las series elaboradas permiten observar, además, los profundos contrastes entre las economías y las industrias petroleras de México y Venezuela ya que, a las ya mostradas, es necesario añadir las series de contabilidad nacional histórica (ingreso neto, ahorro, depreciación de capital físico), precios del petróleo, costes laborales e inversión en la industria petrolera, exploración y reservas, por citar las más importantes.

Hay que destacar que no sólo se amplían los horizontes de la historia económica gracias a la aplicación de la contabilidad medioambiental; también la contabilidad medioambiental se beneficia del uso de series históricas. El largo plazo es un excelente laboratorio para el análisis ex-post de conceptos, modelos y métodos de contabilidad medioambiental. No en vano se reconoce que "es necesario no sólo desarrollar mejores modelos, sino también dedicar más esfuerzo a la verificación de los modelos a través de comparaciones a posteriori de las predicciones teóricas con los resultados observados"18. En parte, este estudio viene a enlazar "el considerable progreso hecho a la hora de resolver los problemas teóricos básicos con la falta de acuerdo en el lado empírico sobre los métodos más apropiados para realizar ajustes específicos $^{\prime 19}$. Es precisamente en este punto donde la aplicación de métodos alternativos a contextos nacionales diferentes se convierte en crucial. Originalmente, los ejercicios de evaluación y ajuste que aquí se realizan tenían el objetivo de comparar las diferentes estrategias de explotación llevadas a cabo por ambos países a la luz de los métodos propuestos por la contabilidad medioambiental. A la larga, esos mismos ejercicios desvelan aspectos que los planteamientos teóricos no contemplaban y ponen en tela de juicio algunos de los supuestos de partida de los métodos sugeridos desde la contabilidad medioambiental. La confrontación de datos históricos con los modelos teóricos ofrece la posibilidad de identificar omisiones en la contabilidad medioambiental que no son observables en ejercicios de corto plazo.

\footnotetext{
Nordhaus y Kokkenlenber (1999), p. 44.

Las más de setenta páginas del apéndice estadístico de Rubio (2002) avalan esta afirmación.

Bartelmus, Lutz y Van Tongeren (1993), p. 177.

Freeman (1993), p. 14.

Vincent (2000), p. 23.
} 


\section{5. ¿Cuáles son las implicaciones de esta investigación?}

Si los planteamientos de la contabilidad medioambiental resultaran correctos, las posiciones de la historiografía que enfatizan lo efímero de las prosperidades mexicana y venezolana recibirían un apoyo cuantitativo. Colateralmente, se obtiene por primera vez una visión cuantitativa comparada de las industrias petroleras de ambos países para todo el siglo XX. Este contraste puede iluminar las discusiones políticas e ideológicas que se han mantenido desde ambos lados acerca de la bondad de la estrategia elegida. En sí mismo, este análisis constituye una contribución significativa a la historia económica comparada de los dos países. El estudio viene a cuestionar si es apropiado el uso de la contabilidad nacional tradicional en el caso de países productores de petróleo y en economías basadas en recursos naturales en general. En el corazón de este cuestionamiento se halla el debate sobre el concepto de ingreso nacional y, en particular, sobre el de ingreso sostenible ${ }^{20}$. Además, al proponer una medida cuantitativa para incluir los recursos naturales en las cuentas nacionales, la contabilidad medioambiental quizá sirva para abrir una puerta que permita reexaminar viejos debates de historia económica. En uno de sus más famosos artículos, Abramovitz reconoce que sus medidas de convergencia no tienen en cuenta la variación en la riqueza natural de los países en relación a su población, ya que las medidas de productividad reflejan las diferencias en la disponibilidad de recursos naturales así como en los niveles tecnológicos ${ }^{21}$. Este problema podría abordarse de tener medidas estandarizadas que permitieran incluir los recursos naturales en los cálculos. Al mismo tiempo, las consideraciones metodológicas que se derivan de este estudio invitan a introducir mejoras en la contabilidad medioambiental, al mostrar inconsistencias y hacer aclaraciones sobre métodos y convenciones aplicadas. Si las herramientas desarrolladas por la contabilidad medioambiental prueban ser útiles en perspectiva histórica, se emplearán con creciente confianza en el futuro. Finalmente, el análisis de dos estrategias muy diferentes en el uso de los recursos naturales podría generar nuevas cuestiones para el debate del crecimiento sostenible. Por tanto, los resultados obtenidos pueden tener implicaciones de política económica sobre el uso de los recursos naturales.

20 La literatura en este campo aumenta exponencialmente. Para un repaso de la publicada hasta 2001, Rubio (2002), cap. 2.

21 Abramovitz (1986), pp. 392-393. 


\section{Teoría y métodos de contabilidad medioambiental: algunos princi- pios básicos}

En palabras de la Comisión Europea, "hasta la fecha no existe ningún sistema que describa enteramente el medio natural, por lo que parece que un sistema integrado de contabilidad medioambiental económica no es alcanzable en este momento. Esta situación, no debe sin embargo, impedir que nos esforcemos en ello"22. Efectivamente, no existe hasta la fecha un acuerdo consensuado sobre la forma de integrar el medio ambiente en los indicadores macroeconómicos; en su lugar, distintos planteamientos teóricos, métodos empíricos y objetivos compiten en el ámbito de la contabilidad medioambiental ${ }^{23}$. Existen al menos tres formas alternativas de integración del medio natural con los indicadores macroeconómicos al uso ${ }^{24}$. A saber: a) la inclusión directa en el sistema de contabilidad nacional actual; b) el desarrollo de una contabilidad satélite, específica del medio ambiente, pero paralela — no integrada - al sistema de cuentas nacionales; c) la generación de un nuevo sistema, más ambicioso y sofisticado, de cuentas económicas y ambientales integrado. Un examen detallado de cada una de estas alternativas excede con mucho el espacio de este artículo. Baste decir aquí que, realizado ese examen, las opciones que aparecen como más útiles y factibles a los efectos expuestos más arriba son el ajuste directo sobre las cuentas nacionales existentes y la realización de la parte correspondiente a los recursos naturales no renovables del sistema integrado de cuentas económicas y ambientales.

Expliquemos brevemente la lógica de ajustar el sistema de contabilidad nacional teniendo en cuenta el deterioro medioambiental. Partiendo del agregado tradicional del PIB, no es posible distinguir si una nación está acumulando capital o viviendo a costa de dilapidarlo. Las medidas netas (el Producto Interior Neto o el Producto Nacional Neto) descuentan el coste correspondiente al deterioro del stock de capital ocurrido durante el proceso de producción actual, esto es, la depreciación de capital. Teniendo en cuenta ciertos matices y bajo determinados supuestos, el Producto Nacional Neto (PNN) a precios de mercado es, en la práctica, la mejor aproximación factible a lo que sería un ingreso sostenible, o lo que es igual, la definición de ingreso de Hicks ${ }^{25}$. Al mismo tiempo, Weitzman (2000) demostró que el PNN a precios de mercado es la anualidad equivalente o nivel estacionario del consumo futu-

\footnotetext{
European Commission (1994), p. 21.

Lutz (1993).

Norgaard (1989), p. 54.

En el original: "the largest permanently maintainable level of consumption sustained on those receipts that are not derived at the expense of declining capital", Hicks (1946), p. 173. La demostración teórica de la identidad entre el ingreso definido por Hicks y el Producto Nacional Neto la hizo Weitzman (1976).
} 
ro. En otras palabras, el PNN ofrece información sobre las posibilidades de consumo del país en el largo plazo, lo que él definió como welfare income. La implicación directa para la contabilidad medioambiental es que el ingreso neto tradicional no toma en cuenta el desgaste medioambiental, que se asimila en este caso a la depreciación de capital, sólo que aquí la depreciación del capital natural es lo que debería considerarse. Dado que la contabilidad nacional omite la depreciación del capital natural, las medidas tradicionales de ingreso neto pierden su condición de indicadores de ingreso sostenible y no sirven para averiguar las verdaderas posibilidades de consumo de la economía a largo plazo. El ajuste, por tanto, intenta contestar dos preguntas diferentes pero relacionadas: ¿Cuál es el verdadero ingreso de esta economía? ¿Qué debe hacerse para asegurar que el nivel de ingreso sea sostenible? Las dos se relacionan en tanto que el futuro de la economía está condicionado por las decisiones de consumo e inversión hechas en el tiempo presente. Los dilemas teóricos se han resuelto mayoritariamente a favor de esta manera de entender el ingreso sostenible con la inclusión de la degradación medioambiental como coste de depreciación del capital natural.

La manera concreta de calcular el ajuste, empero, está lejos de haber sido resuelta. En principio, la depreciación de un bien corresponde a su cambio de valor entre dos momentos en el tiempo. La literatura expone al menos cuatro métodos alternativos de realizar el cálculo del valor y también de la depreciación de un activo, cuando se trata de un activo agotable. El Cuadro 1 resume las distintas especificaciones matemáticas. Dos de ellas, precio neto y coste de usuario (net price y user cost) han sido ampliamente utilizadas en estudios empíricos de contabilidad medioambiental a la hora de incluir la depreciación de recursos naturales no renovables; las otras dos (valor presente y valor imputado) no han pasado de ser sugerencias teóricas sobre cómo realizar el ajuste ${ }^{26}$. Pese a partir de fundamentos teóricos diferentes con respecto al concepto de ingreso, se puede demostrar que: 1) el ajuste del PNN propuesto desde los cuatro métodos se puede expresar en el marco de la ecuación fundamental de valoración de activos; 2 ) todos los métodos requieren una estimación de la renta generada por el recurso natural $(\mathrm{N} t)$ en el año t para obtener un cálculo del ajuste; y 3) la implementación de cada método difiere de los otros en función de los supuestos que cada uno hace en relación al comportamiento esperado de las rentas en el futuro.

26 El método de precio neto es una contribución de Repetto (1989); el de coste de usuario se atribuye a El Serafy (1989); la aplicación del valor presente a la valoración de recursos naturales y su depreciación se puede encontrar en Hartwick y Hageman (1993); y el método del valor imputado es una contribución teórica de Sefton y Weale (1996). Para los métodos de El Serafy y Repetto existe una buena síntesis en castellano (desde un punto de vista económico-ecológico) en el manual de Martínez y Roca (2000), pp. 84-101. 


\section{CUADRO 1}

ECUACIONES DE AJUSTE DE LOS DISTINTOS MÉTODOS DE CONTABILIDAD MEDIOAMBIENTAL

\begin{tabular}{|c|c|c|}
\hline Método & Valor asignado al recurso & Cálculo de la depreciación \\
\hline \multirow[b]{2}{*}{$\begin{array}{c}\text { Valor } \\
\text { presente }\end{array}$} & & $V_{t+1}-V_{t}=$ \\
\hline & $V_{t}=\sum_{n=0}^{n=\left(R_{t} / q_{t}\right)} \frac{N_{t+n}}{(1+i)^{n}}$ & {$\left[\sum_{n=0}^{n=\left(R_{1+t} / q_{t+1}\right)} \frac{N_{t+1+n}}{(1+i)^{n}}\right]-\left[\sum_{n=0}^{n=\left(R_{t} / q_{t}\right)} \frac{N_{t+n}}{(1+i)^{n}}\right.$} \\
\hline $\begin{array}{l}\text { Precio } \\
\text { neto }\end{array}$ & $V_{t}=\left(q_{t}+q_{t+1}+q_{t+2}+\ldots . .+q_{t+n}\right) u_{t}=u_{t} Q$ & $-q_{t} u_{t}=-q_{t}\left(p_{t}-m c_{t}\right)=-N_{t}$ \\
\hline $\begin{array}{l}\text { Coste de } \\
\text { usuario }\end{array}$ & $V_{t}=\sum_{n=0}^{n=\left(R_{t} / q_{r}\right)} \frac{N_{t}}{(1+i)^{n}}$ & $-N_{t} /(1+i)^{n+1}$ \\
\hline $\begin{array}{c}\text { Valor } \\
\text { imputado }\end{array}$ & $V_{t}=U_{t} Q_{E}$ & $-N_{t}+\left(V_{t}(\mathrm{i} /(1+\mathrm{i}))\right)=-\mathrm{N}_{t}+\left(\mathrm{u}_{t} \mathrm{Q}_{\mathrm{E}}(\mathrm{i} /(1+\mathrm{i}))\right)$ \\
\hline
\end{tabular}

\section{Siendo:}

$\mathrm{Vt}=$ valor del recurso.

qt $=$ cantidad extraída.

ut $=$ pt-mct $=$ renta de Hotelling por unidad.

$\mathrm{pt}=$ precio de venta unitario.

mct $=$ coste marginal de extracción.

$\mathrm{Nt}=$ renta total.

$\mathrm{nt}=\mathrm{Rt} / \mathrm{qt}=$ esperanza de vida del recurso.

$\mathrm{Rt}=$ reservas.

$Q=$ suma acumulativa de las extracciones futuras.

$\mathrm{QE}=$ stock del recurso con destino la exportación.

El valor del recurso hoy $(\mathrm{Vt})$ depende de las expectativas que tengamos en cuanto a la renta que éste generará en el futuro ${ }^{27}$. Es ahí donde difieren los métodos. Mientras que el método de precio neto y el de valor imputado parten de supuestos de extracción óptima, donde la renta por unidad de recurso extraído debería comportarse siguiendo la regla de Hotelling (incrementándose como el tipo de interés a medida que aumenta la escasez del recurso), el coste de usuario estima que el valor

$27 \quad$ Obsérvese que los métodos de contabilidad medioambiental al uso tratan de evitar el cálculo del valor del capital natural para concentrarse exclusivamente en el cálculo de su depreciación. Para obtener una idea del valor del capital petrolero venezolano, véase Aniyar (2003). 
del recurso ha de calcularse suponiendo que las rentas se mantendrán como en el año presente, y el método del valor presente puede calcularse con cualquiera de esos supuestos, o utilizando las rentas reales históricas obtenidas. Obviamente la estimación del ajuste, es decir, la asignación de un valor a la depreciación del recurso natural, varía ampliamente en todos estos casos.

Una de las conclusiones más importantes derivadas del análisis comparativo de los métodos teóricos de ajuste, es que en realidad no se trata de métodos alternativos, sino de métodos pensados para escenarios distintos. Mientras que Hartwick (1990) implícitamente apunta a que el coste de usuario no es aplicable en casos de economías cerradas, Sefton y Weale (1996) argumentan que el método del precio neto no es apropiado en economías abiertas, admitiendo que el coste de usuario y su propio método sólo son válidos tratándose de economías que comercian el recurso natural con el exterior. Esto es así porque, en su cálculo, incluyen la posibilidad de que el exportador de recursos naturales obtenga ganancias adicionales por la mejora en los términos de intercambio en el futuro, que le permitirían consumir más en el presente ya que esa mejora garantizaría el consumo futuro. Dadas las especificaciones de los casos históricos a ajustar, queda claro que en cada uno de ellos se habrán de aplicar los métodos diseñados para su categoría de economía abierta o cerrada.

\section{Contabilidad nacional ambiental para México y Venezuela: 1900-198928}

Como se ha dicho más arriba, las estrategias aplicadas respecto a la explotación petrolera fueron muy diferentes en México y Venezuela durante el siglo XX. Mientras la administración mexicana consideró que la mejor manera de utilizar su riqueza petrolera era proveyendo energía barata para la industrialización del país, los gobiernos venezolanos mantuvieron que el papel que debía desempeñar este recurso era el de financiar el desarrollo nacional. Las distintas estrategias tuvieron efectos sobre todos los ámbitos de la explotación petrolera: legislación, gestión (pública frente a privada), ritmo de exploración de nuevos yacimientos y empleo en la industria, entre otros. Las diferencias en éstos dos últimos pueden apreciarse en el Cuadro 2 y en el Gráfico 5, respectivamente.

28 Los datos recopilados se extienden en su mayoría hasta 1985, con algunas incursiones hasta 1989. Los cambios habidos en las décadas siguientes, en particular en Venezuela, merecerían un análisis propio, pero desafortunadamente los datos no están, hoy por hoy, disponibles. 


\section{CUADRO 2}

RESERVAS PETROLERAS Y RATIO PRODUCCIÓN/RESERVAS EN MÉXICO Y VENEZUELA, 1920-1990

(millones de barriles)

\begin{tabular}{|c|c|c|c|c|c|c|c|c|c|}
\hline \multicolumn{3}{|c|}{ México } & \multicolumn{2}{|c|}{ Venezuela } & \multicolumn{3}{|c|}{ México } & \multicolumn{2}{|c|}{ Venezuela } \\
\hline Años & Reservas & Ratio & Reservas & Ratio & Años & Reservas* & Ratio & Reservas & Ratio \\
\hline 1920 & 1.208 & 7,7 & 106 & 29,6 & 1960 & 4.787 & 29,3 & 17.402 & 16,7 \\
\hline 1930 & 1.246 & 31,5 & 1.258 & 9,3 & 1970 & 5.568 & 19,7 & 13.762 & 10,2 \\
\hline 1940 & 1.225 & 25,4 & 4.605 & 25,1 & 1980 & 60.126 & 63,0 & 19.687 & 24,8 \\
\hline 1950 & 1.608 & 19,1 & 8.724 & 16,0 & 1990 & 65.500 & 55,4 & & \\
\hline
\end{tabular}

* Hay que advertir que México ha estado ajustando sus reservas petroleras a la baja en los últimos años, lo que hace sospechar de las cifras de reservas que recogidas a partir de 1974.

Fuentes: Rubio (2004), Apéndice E.

El Cuadro 2 demuestra el escaso avance de las reservas mexicanas hasta el último tercio del siglo, consecuencia en parte de los problemas financieros de la compañía nacional mexicana, Petróleos Mexicanos (PEMEX). Mientras, el ritmo de descubrimientos de nuevos yacimientos en Venezuela siempre fue intenso, pero dado el veloz ritmo de extracción, las reservas venezolanas siempre contaron con menor esperanza de vida (ratio producción/reservas) que las mexicanas. Al mismo tiempo, el Gráfico 5 invita a plantearse la eficiencia de la estrategia mexicana. Los datos presentados sugieren que, durante la mayor parte del período posterior a la nacionalización, los costes en que incurrió la industria mexicana podrían haberse reducido recortando la inmensa mano de obra empleada por PEMEX (totalmente desproporcionada con respecto al petróleo extraído), o bien aumentando la producción para aprovechar las economías de escala — como sucedería a partir de 1974-1975-. Estas diferencias, en esperanza de vida del recurso y costes de producción, van a tener un papel fundamental a la hora de calcular la renta $(\mathrm{Nt})$ asignada al recurso y, por tanto, van a influir en el resultado del ajuste.

Hacer encajar el mundo real en los modelos teóricos presentados en la sección anterior es una tarea ardua. Existen amplias discrepancias entre la evolución histórica de las variables necesarias para el cálculo y los supuestos adoptados en los modelos teóricos. La teoría impone a la extracción una serie de supuestos muy restrictivos (extracción óptima, reservas homogéneas, ausencia de cambio tecnológico, etc.), los cuales se encuentran muy alejados de las características reales de la explotación petrolera en la mayoría de países (en presencia de monopolios y oligopolios y constantes avances tecnológicos, por ejemplo). Además, las series requeridas casi nunca 


\section{GRÁFICO 5}

EMPLEADOS DE LAS INDUSTRIAS PETROLERAS DE MÉXICO Y VENEZUELA, 1921-1988

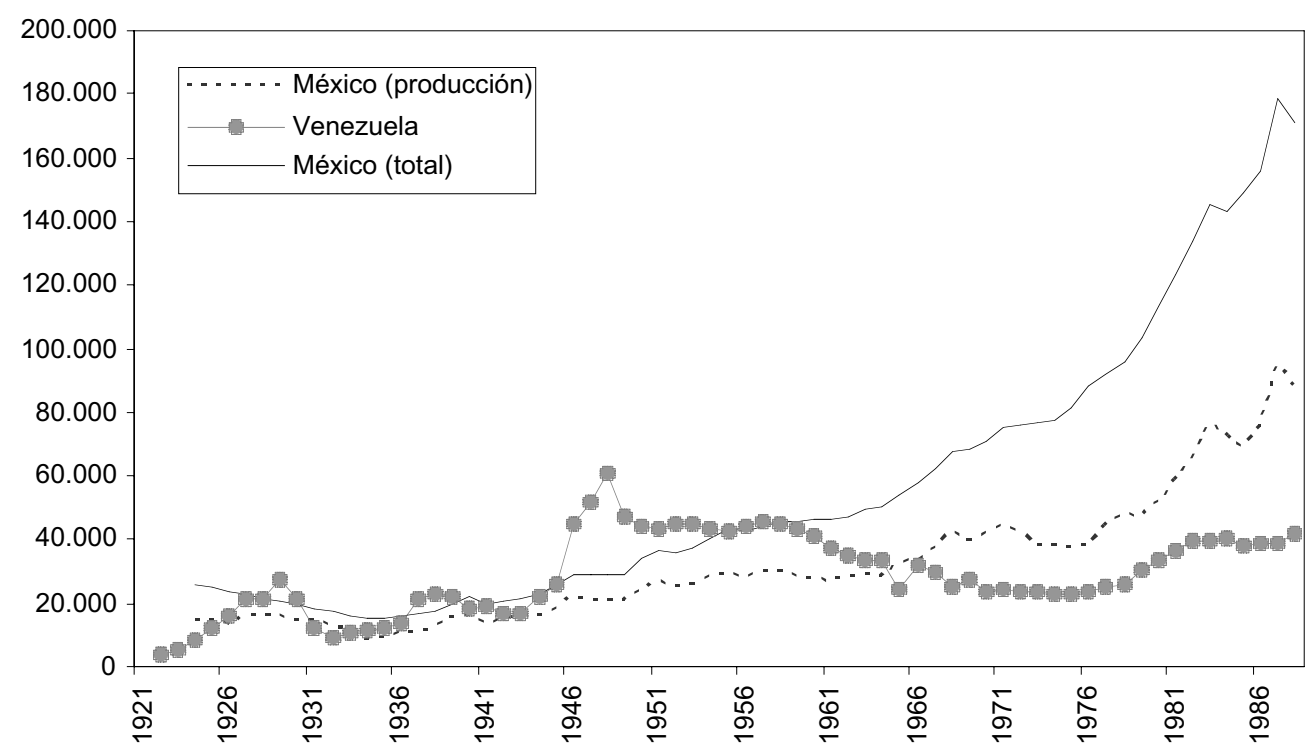

Fuentes: Manterola (1938) para empleados totales en la industria petrolera mexicana en 1934-1935 e INEGI (1994a) en 1938-1988. Estimación propia de los empleados dedicados a la producción. Datos venezolanos de Baptista (1997).

se encuentran disponibles, y es necesario sustituirlas por series alternativas. La definición teórica de la renta por unidad de recurso extraída, $\left(u_{t}\right)$, es precio menos coste marginal, que tras multiplicarse por la cantidades extraídas se convierte en renta total, (Nt). Los costes, marginales o no, de la industria petrolera son uno de los misterios mejor guardados por ésta. Así pues, la mayoría de los trabajos empíricos optan por calcular costes medios, o lo que es lo mismo, la renta se calcula como la diferencia entre el precio unitario y los costes de producción (generalmente costes laborables más costes de capital). El resultado del cálculo de la renta como se ha especificado se muestra en el Gráfico $6^{29}$.

Los datos que aquí se presentan corresponden a la estimación media que se considera más apropiada después de generar resultados utilizando análisis de sensibilidad, variando tanto los supuestos sobre los retornos del capital como los costes (se utilizaron costes marginales con cálculos alternativos y costes medios utilizando diferentes datos de costes de explotación y salarios). Los resultados de estos cálculos alternativos se pueden consultar en Rubio (2002). 


\section{GRÁFICO 6}

RENTAS PETROLERAS DE MÉXICO Y VENEZUELA, 1920-1985

(millones de dólares)

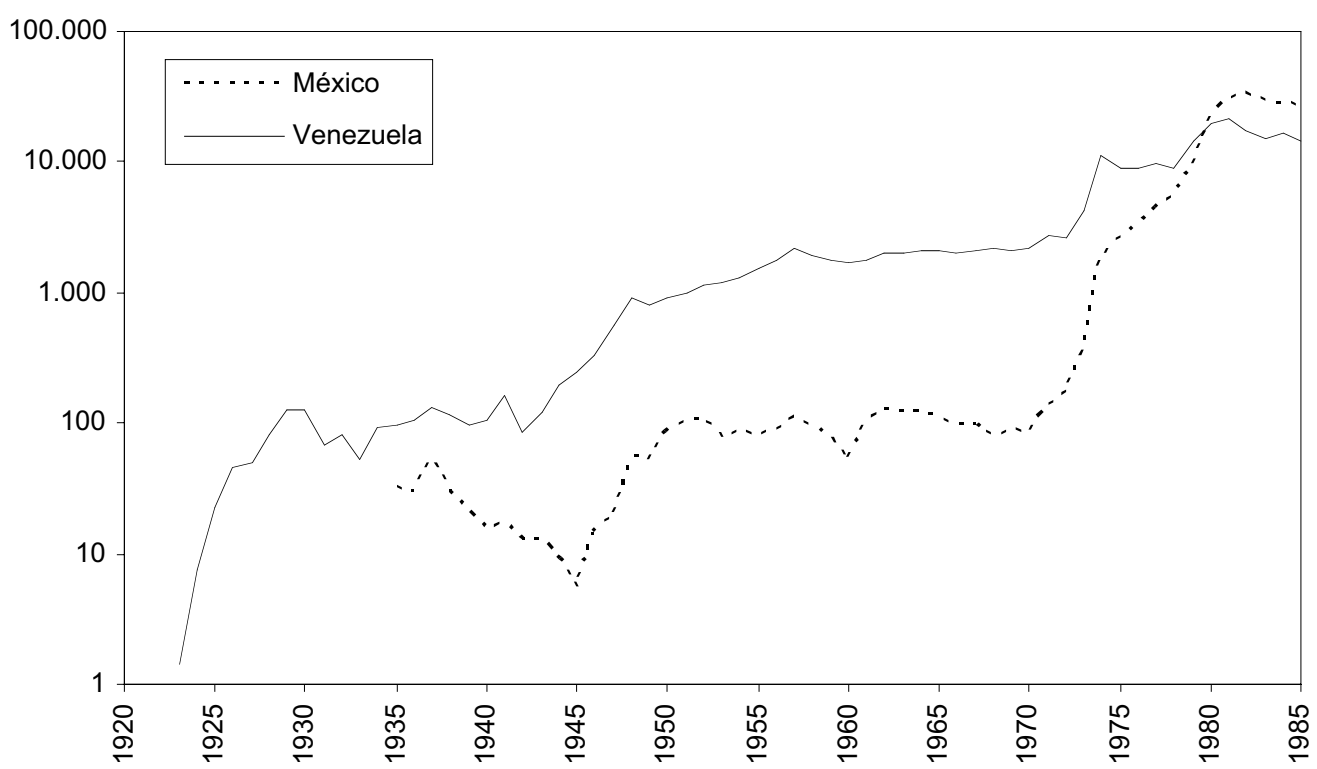

Fuentes: Rubio (2002).

Una observación simple pero crucial se deriva del análisis de la evolución histórica de las rentas: ni fueron constantes, ni crecieron al ritmo marcado por los tipos de interés. Ninguno de los supuestos de partida de los modelos en cuanto a la evolución de las rentas se cumple en términos históricos. Según los modelos teóricos, los costes marginales deberían ser crecientes con la escasez, por lo tanto utilizar costes medios - lo que implica costes marginales constantes- exageraría el tamaño de la renta y de la depreciación. Sin embargo, la proporción de la renta con respecto al precio del barril de petróleo ha crecido durante el siglo XX, lo cual, dada la estabilidad de los precios hasta 1974, implica que los costes de producción declinaron sistemáticamente con relación al precio del petróleo. Esto contrasta radicalmente con los costes marginales constantes o crecientes sistemáticamente asumidos en las discusiones teóricas sobre extracción de recursos. Seguramente la omisión del cambio tecnológico en los modelos teóricos explica una gran parte de la diferencia entre las evoluciones histórica y teórica de costes y rentas. Pero no son los costes los únicos que discrepan en realidad de los modelos teóricos. La mayoría de éstos parten de la premisa 
de que el stock de capital es fijo y la extracción se realiza a ritmo constante en el tiempo, lo cual implica necesariamente que la variable producción/reservas empequeñezca también de manera constante. Esta variable es fundamental en el cálculo tanto del valor del recurso como de su depreciación, como se observa en el Cuadro 1, donde se muestran las ecuaciones de cálculo. En los casos históricos a los que nos enfrentamos, la variable producción/reservas varía ampliamente durante el siglo, como se ha visto en el Cuadro 2. Esta variación no se debe exclusivamente al descubrimiento de nuevos yacimientos, sino también a las alteraciones en el ritmo de extracción a lo largo del tiempo. El valor del recurso usando series históricas es mucho más variable que en los modelos teóricos, en parte debido al valor cambiante de esta variable.

Hemos visto antes que los métodos que la literatura considera como alternativas válidas para el cálculo de la depreciación de los recursos naturales son, en realidad, métodos que se aplican a escenarios diferentes. Mientras que el precio neto es el ajuste correcto en economías cerradas, las economías abiertas necesitan imputar un ingreso adicional a la cantidad del recurso que se exporta fuera del país; si el país exportara todo su recurso, entonces el método del coste de usuario se aproxima perfectamente el método del coste imputado. Siendo esto así, cada uno de los dos casos históricos presentados requerirá un ajuste diferente. México, en cuanto al petróleo, se puede considerar una economía cerrada entre 1938 y 1974, mientras que Venezuela se asemeja al caso de una economía abierta. Por lo tanto, el precio neto sería el método correcto a aplicar para ajustar el ingreso mexicano, mientras que el coste de usuario debería ser el aplicado al caso venezolano. Convendría tener en cuenta, asimismo, que dadas las ecuaciones de ajuste, al aplicar el método de valor imputado a México se elimina la necesidad de cambiar de método cuando se modifica la política exportadora del país, ya que si no se exporta nada, el segundo término del ajuste se elimina de la ecuación, y lo que queda es precisamente el precio neto (o lo que es lo mismo, la renta, $\mathrm{N}_{\mathrm{t}}$ ). Al mismo tiempo, dada la voracidad exportadora venezolana, el método de valor imputado sería prácticamente equivalente a usar el método de coste de usuario. Es por tanto posible aplicar el método de valor imputado a ambos casos respetando sus especificaciones de economía abierta frente a economía cerrada. Hay que hacer, sin embargo, una importante precisión. El valor imputado a las ganancias debidas a los términos de intercambio en el modelo teórico son ganancias teóricas esperadas. Rubio (2004) demuestra que las ganancias esperadas teóricamente estimadas por Sefton y Weale no responden a la evolución histórica de los términos de intercambio de los países productores de petróleo, sobreestimándolos gravemente; por tanto, el consumo presente debería ser menor de lo permitido por dicho modelo. El ajuste, pues, se realiza aquí contando con la evolución real de los términos de intercambio de acuerdo con los resultados obtenidos por Rubio (2004). Dicho ajuste responde a la 
siguiente formulación PNNadj=PNNtrad-Nt+TI; el producto nacional neto tradicional se revisa restando la depreciación de capital, pero admitiendo que puede producirse una compensación debido a la mejora en los términos de intercambio. La magnitud del ajuste se observa en el Gráfico 7. La contabilidad nacional histórica tradicional condiciona el año de comienzo de las series, ya que no es posible conseguir medidas netas de producto con anterioridad a 1930.

Uno de los principales objetivos de este estudio era cuantificar las aseveraciones de la contabilidad medioambiental, o en otras palabras, establecer el grado de divergencia entre la contabilidad medioambiental y la contabilidad nacional tradicional. De los resultados del Gráfico 7 se desprende que el ajuste venezolano es verdaderamente importante, ya que situaría el ingreso medioambiental entre un 10 y un 30 por 100 por debajo de las medidas tradicionales de ingreso, que, ahora sabemos, no eran sostenibles. En el caso de México, sólo cuando la extracción petrolera se dispara en los años setenta se observa el impacto sobre el ingreso tradicional que debería verse ajustado entre un 5 y un 20 por 100. El ingreso medioambiental difiere sustancialmente del ingreso tradicional. Es más que probable que el ingreso medioambiental refleje mejor la saturación real de las respectivas economías que los ingresos tradicionales usados hasta el momento. Lo interesante, sin embargo, es que la contabilidad nacional tradicional no exageraría sistemáticamente el ingreso sostenible en presencia de ganancias debidas a los términos de intercambio. Obsérvese que, de haber continuado la mejora de los términos de intercambio de los años 1973 y 1974, Venezuela hubiera contado con un ingreso ajustado superior al medido tradicionalmente. Esto no debe desanimar a los contables medioambientales, ya que lo que de verdad implica es que el desajuste entre las medidas medioambientales y las medidas tradicionales es aún mayor que el previsto en los modelos teóricos.

De acuerdo con estos resultados es difícil seguir considerando a las medidas tradicionales de ingreso como indicadores fiables de sostenibilidad o de las posibilidades futuras de consumo. Los niveles de consumo que se derivan de los niveles de ingreso tradicionales se encuentran por encima de las posibilidades reales de estas economías, que sin embargo, no se colapsaron. Es probable que la explicación a esta última paradoja se encuentre en el cambio tecnológico que permite aumentar la cantidad de recurso disponible año tras año y reduce los costes de producción, ya que está claro que las mejoras en los términos de intercambio no sirven para compensar el empobrecimiento del stock de recursos naturales como se argumenta desde algunos modelos teóricos. Es importante puntualizar que los teóricos habían incluido los términos de intercambio como posible vía de escape al colapso económico, pero no han sido capaces aún de incorporar el cambio tecnológico en sus modelos. 


\section{GRÁFICO 7}

INGRESO AJUSTADO MEDIOAMBIENTALMENTE COMO PORCENTAJE DEL INGRESO TRADICIONAL DE MÉXICO Y VENEZUELA, 1936-1985

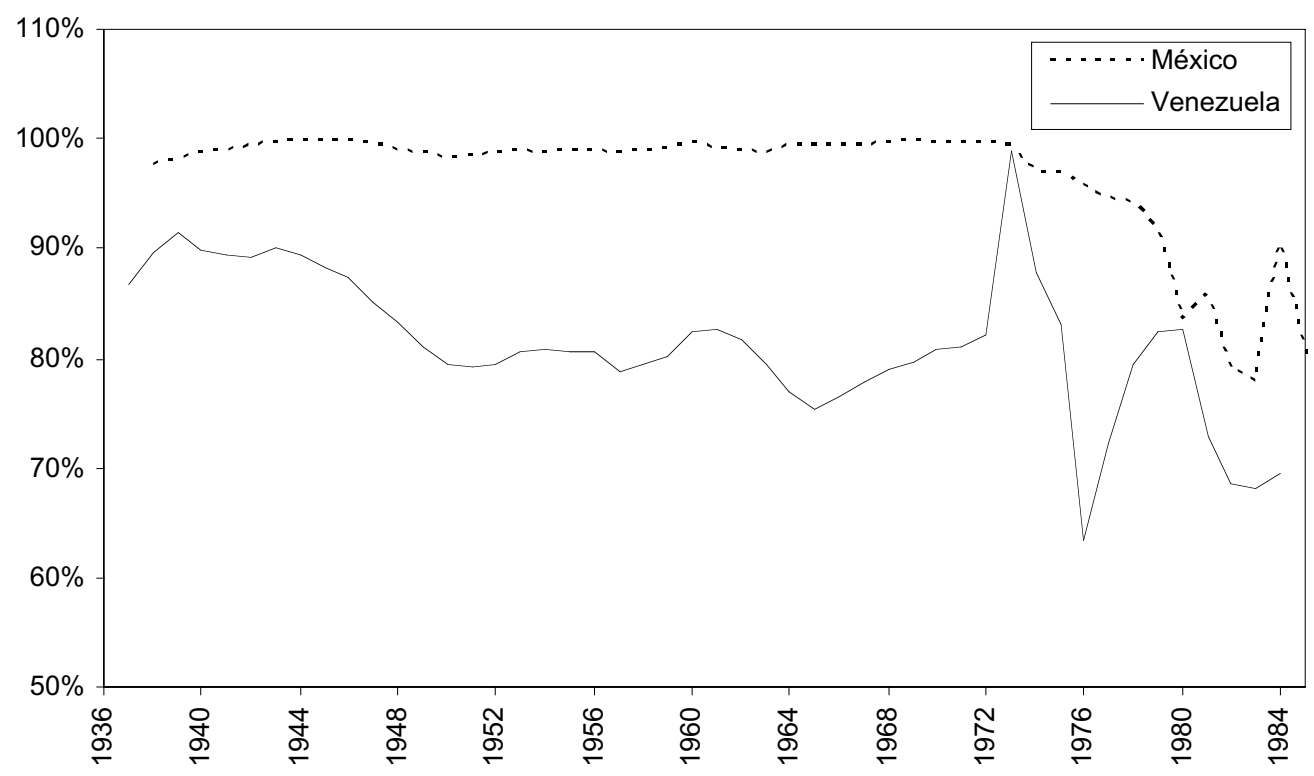

Fuentes: Rubio (2004), Apéndice estadístico.

Estos resultados también tienen implicaciones para el análisis de las diferentes estrategias seguidas por México y Venezuela. Podría parecer a simple vista que la estrategia de puro exportador de recursos seguida por Venezuela es la que de verdad debe preocuparnos en términos de ingreso sostenible. Pero la estrategia mexicana de economía cerrada supone una mayor necesidad de reinvertir para reemplazar el recurso usado (y por tanto consumir menos en el presente), dada la ausencia de ganancias asociadas al comercio en una economía cerrada. El mejor resultado de México en parte responde a la pequeña magnitud de la explotación petrolera. Con un nivel mayor de extracción, su ingreso tradicional se vería aún más ajustado que el de una economía abierta.

El exportador de recursos naturales puede consumir más hoy (no necesita reinvertir la totalidad de la renta generada) no sólo gracias a las ganancias esperadas en los términos de intercambio - a medida que el recurso se hace más escaso-, sino también a que, en el futuro, habrá mayores cantidades disponibles del recurso a costes menores merced al cambio tecnológico. Sin embargo, el cambio técnico es una 
espada de doble filo. En algún momento, ese mismo avance tecnológico puede hacer inservible la totalidad el stock natural - por ejemplo, con el descubrimiento de una nueva fuente de energía-, en cuyo caso ni siquiera el reinvertir la totalidad de la renta en el presente garantizaría el mantenimiento en el futuro de los niveles de consumo actuales.

\section{Conclusiones}

Los resultados presentados aquí son un primer esfuerzo de estimación de indicadores medioambientales y económicamente sostenibles. Se ofrecen con el espíritu de intercambio transparente de resultados de investigación y reflexión, e intentan estimular el diálogo y el avance, tanto en el ámbito metodológico como en el de la aplicación práctica de indicadores de ingreso sostenible. Los resultados obtenidos tienen implicaciones de política económica sobre el uso de recursos naturales, y fundamentan recomendaciones derivadas de los ajustes medioambientales. Dijimos al principio que si las herramientas de contabilidad medioambiental resultaban útiles en perspectiva histórica, ello permitiría su uso con mayor confianza en políticas basadas en sus recomendaciones. Precisamente porque el análisis histórico descubre nuevos aspectos a tener en cuenta, este estudio también contribuye a mejorar tales indicadores para poder usarlos con un mayor grado de fiabilidad.

\section{Bibliografía}

ABRAMOVITZ, Moses (1986): "Catching up, forging ahead and falling behind", Journal of Economic History, 46, 2, pp. 385-406.

ACOSTA SAIGNES, Miguel (1941): Petróleo en México y Venezuela, México D. F., Morelos.

ANIYAR, Sara (2003): Estimating the Value of Oil Capital in a Small Open Economy: the Venezuela's Example, Documento de Trabajo 108.2003, The Fondazione Eni Enrico Mattei, Note di Lavoro Series.

ARCILA FARIAS, Eduardo (1989): “ ¿En qué medida se ha cumplido el vaticinio de Uslar Pietri (Ahora, 1936) sobre el parasitismo rentista en la Venezuela petrolera?, ¿En qué medida se ha sembrado el petróleo?, ¿Cuál es el significado del momento actual en esta evolución?", en MIERES, Francisco (ed.), Hacia la Venezuela Post-petrolera, Caracas, Academia Nacional de las Ciencias Económicas, Vol. 1, pp. 123-130. 
BAPTISTA, Asdrúbal (1991): Bases cuantitativas de la economía venezolana, 1830-1989, Caracas, Fundación Polar.

—(1997): Bases cuantitativas de la economía venezolana. 1830-1995, Caracas, Fundación Polar.

BARTELMUS, Peter; LUTZ, Ernst, y VAN TONGEREN, Jan (1993): “Environmental Accounting : an operational perspective", en SERAGELDIN, Ismail, y STEER, Andrew (eds.), Valuing The Environment: Proceedings of the First Annual International Conference on Environmentally Sustainable Development held at the World Bank, Washington D. C., The World Bank.

CARRILLO BATALLA, Tomás Emilio (1968): "El ingreso fiscal petrolero", en CARRILLO BATALLA, Tomás Emilio, La evaluación de la inversión del ingreso fiscal petrolero en Venezuela [conferencia celebrada en Universidad Central de Venezuela. Foro Petrolero 1965], Caracas, UCV/FACES, Colección Foros y Seminarios, Serie Foros, 5, pp. 11-65.

COATSWORTH, John H., y TAYLOR, Alan M. (eds.) (1999): Latin America and the World Economy since 1800, Cambridge, Cambridge University Press.

DASGUPTA, Partha, y MÄLER, Karl G. (1991): “The Environment and Emerging Developing Issues", en Proceedings of The World Bank Annual Conference on Development and Economics, New York, The World Bank.

DEANE, Phyllis, y COLE, W. A. (1959): British Economic Growth, 1688-1959: Trends and Structure, Cambridge, University of Cambridge, Department of Applied Economics, Monographs, Vol. 8.

EL SERAFY, Salah (1989): “The Proper Calculation Of Income From Depletable Natural Resources", en AHMAD, Yusuf J.; SERAFY, Salah El, y LUTZ, Ernst (eds.), Environmental Accounting For Sustainable Development, a UNEP-World Bank Symposium, Washington D. C., The World Bank, pp. 10-18.

EUROPEAN COMMISSION, EUROSTAT (1994): European System for the Collection of Economic Data on the Environment (SERIEE), 1994 version, Brussels, European Commission.

FEINSTEIN, Charles (1972): National Income, Expenditure and Output of the United Kingdom, 1855-1965, Cambridge, Cambridge University Press.

FREEMAN, A. Myrick (1993): The Measurement of Environmental and Resource Values: Theory and Methods, Washington D. C., Resources for the Future.

HARTWICK, John M. (1990): “Natural resources, national accounting and economic depreciation", Journal of Public Economics, 43, pp. 291-304.

HARTWICK, John, y HAGEMAN, Anja (1993): “Economic depreciation of mineral stocks and the contribution of El Serafy", en LUTZ, Ernst. (ed.), Toward Improved Accounting for the Environment: An UNSTAT-World Bank Symposium, Washington D. C., The World Bank. 
HICKS, John R. (1946): Value and Capital: An inquiry into some Fundamental Principles of Economic Theory, Oxford, Oxford University Press.

HOFMAN, André A. (2000): The Economic Development of Latin America in the Twentieth Century, Cheltenham, Elgar.

KAPLAN, Martín (comp.) (1981): Petróleo y desarrollo en México y Venezuela, México D. F., UNAM y Nueva Imagen.

KUZNETS, Simon (1951): Income and Wealth Series, Cambridge, Cambridge University Press.

LUTZ, Ernst (ed.) (1993): Toward Improved Accounting for the Environment: An UNSTAT-World Bank Symposium, Washington D. C., The World Bank.

MADDISON, Angus (1995): Monitoring the World Economy, 1820-1992, París, OCDE.

MARTÍNEZ ALIER, Joan, y ROCA JUSMET, Jordi (2000): Economía ecológica y política ambiental, México D. F., FCE/PNUMA.

MATOS ROMERO, Manuel (1939): Venezuela y México ante el Imperialismo, Maracaibo, Empresa Panorama.

INSTITUTO NACIONAL DE ESTADÍSTICA, GEOGRAFÍA E INFORMÁTICA (INEGI) (1994a): Estadísticas históricas de México, México D. F.

-(1994b): Sistema de Cuentas Nacionales de México 1989-1992. Resumen General, Vol. I, México D. F.

MANTEROLA, Miguel (ed.) (1938): La Industria del Petróleo en México, México D. F., Secretaría de Hacienda y Crédito Público, Dirección General Técnica de Ingresos, Oficina de Investigaciones Económicas.

MIERES, Francisco (ed.) (1989): Hacia la Venezuela Post-petrolera, Vol. 1, Caracas, Academia Nacional de las Ciencias Económicas.

MOMMER, Bernardo, y BAPTISTA, Asdrúbal (1983): El Petróleo En Las Cuentas Nacionales: Una Proposición, Working Paper IESA 10.

NAIM, Moses, y PIÑANGO, Ramón (eds.) (1974): El caso Venezuela: una ilusión de armonía, Caracas, IESA.

NORDHAUS, William D., y KOKKENLENBER, Edward. C. (eds.) (1999): Nature's Numbers: Expanding the U. S. National Economic Accounts to Include Environment, Washington D. C., The National Academic Press.

NORGAARD, Richard B. (1989): "Linkages between Environmental and National Income Accounts", en AHMAD, Yusuf J.; SERAFY, Salah El, y LUTZ, Ernst (eds.), Environmental Accounting For Sustainable Development, a UNEP-World Bank Symposium, Washington D.C., The World Bank, pp. 54-58.

OHKAWA, Katzusi (1957): The Growth Rate of the Japanese Economy since 1878, (Economic Research Series I, Institute of Economic Research, Hitsubashi University), Tokyo, Kinokuniya Bookstore. 
PALACIO SOLANO, Isaac Fernando (1996): América Latina: el estigma del petróleo. México, Ecuador y Venezuela, México D. F., El Caballito/IIEc.-UNAM.

PRADOS DE LA ESCOSURA, Leandro (1988): De Imperio a Nación: el crecimiento económico español (1730-1930), Madrid, Alianza.

REPETTO, Robert (1989): Wasting Assets: Natural Resources in the National Income Accounts, Washington D. C., World Resources Institute.

RODRIGUEZ, Francisco, y SACHS, Jeffrey D. (1999): “Why do resource-abundant economies grow more slowly?", Journal of Economic Growth, 4, pp. 277-303.

RUBIO VARAS, María del Mar (2002): Towards Environmental Historical National Accounts for Oil Producers: Methodological Considerations and Estimates for Venezuela and Mexico over the 20th Century, Tesis Doctoral inédita, London School of Economics.

-(2004): "The capital gains from trade are not enough: evidence from the environmental accounts of Venezuela and Mexico", Journal of Environmental Economics and Management, 48, 3, pp. 1.175-1.191 (los apéndices en http/www.econ.iastate. edu/jeem/supplement/MS13021.pdf).

SANGINÉS VILLAVALVA, Esther (1938): “La industria petrolera en México”, Revista de Hacienda, II, Marzo.

SEFTON, James. A., y WEALE, Martin R. (1996): “The net national product and exhaustible resources: The effects of foreign trade", Journal of Public Economics, 61, pp. 21-47.

THYNNE, J. Franklin (1995): British Policy On Oil Resources 1936/1951: With Particular Reference to Mexico, Venezuela and Persia, Trabajo de Investigación inédito, London School of Economics.

USLAR PIETRI, Arturo (1936): "Siembra del petróleo", Ahora, 14 de Junio.

-(1945): Sumario de Economía Venezolana, Caracas, Litografía y Tipografía del Comercio.

-(1966): De una a otra Venezuela, Caracas, Monte Ávila.

-(1985): "Los males del petróleo", El Nacional, 28 de Abril.

VINCENT, Jeffrey R. (2000): "Green accounting: from theory to practice", Environment and Development Economics, 5, pp. 13-24.

WEITZMAN, Martin L. (1976): “On the Welfare Significance of National Product in Dynamic Economy", Quarterly Journal of Economics, 90, 1, pp. 156-162.

-(2000): "The linearlised Hamiltonian as comprehensive NDP", Environment and Development Economics, 5, pp. 55-68. 